\title{
Assessing Urban Land Use Change in New Braunfels, Texas from 2013 to 2020
}

\author{
M. K. Lasode ${ }^{*}$, I. C. Esobi², C. I. Anyanwu1', D. O. Lasode 3 \\ ${ }^{1}$ Department of Geography, Texas State University, San Marcos, Texas, USA \\ ${ }^{2}$ Department of Food, Nutrition and Packaging Science, Clemson University, Clemson, South Carolina, USA \\ ${ }^{3}$ Africa Regional Centre for Information Science, University of Ibadan, Oyo State, Nigeria \\ Email: ^mkl60@txstate.edu
}

How to cite this paper: Lasode, M. K., Esobi, I. C., Anyanwu, C. I., \& Lasode, D. O. (2020). Assessing Urban Land Use Change in New Braunfels, Texas from 2013 to 2020. Journal of Geoscience and Environment Protection, 8, 232-243.

https://doi.org/10.4236/gep.2020.812014

Received: December 6, 2020

Accepted: December 25, 2020

Published: December 28, 2020

Copyright (c) 2020 by author(s) and Scientific Research Publishing Inc. This work is licensed under the Creative Commons Attribution International License (CC BY 4.0).

http://creativecommons.org/licenses/by/4.0/

\begin{abstract}
Urban cities are the major drivers of economic growth and development. Economic growth and development however results in considerable land cover land use dynamics. This study assessed the dynamics in land cover land use that have occurred in New Braunfels, Texas in the last 7 years (2013-2020) to observe areas in the city that had experienced considerable shifts in land cover and land use. 30-meter resolution Landsat images were used to examine possible changes in land cover land use. New Braunfels was observed to have experienced significant changes in land use especially in developed areas. This change can be attributed to the influx of people into the city, contributing to the need for increased urban development. Analysis of this study shows that about 16\% (about 553 hectares) of forest land cover class and 28\% (about 1139 hectares) of grassland class in time 1 (August 31, 2013) changed to built-up land use class in time 2 (November 5, 2020). A limitation to this study was that of the spatial resolution of images used. Higher spatial resolution images could impact the producers, users, and overall accuracy assessment. Results from this study can aid in supporting better decision-making for sustainable urban development and climate change mitigation.
\end{abstract}

\section{Keywords}

Change Detection, NDVI, Landsat, Land Cover Land Use Change, Urban Environment

\section{Introduction}

Urban land use change is a significant process resulting from global environmental dynamics (Hersperger et al., 2018; Lasode et al., 2021; Verburg et al., 
2015). The formation and operation of an ecosystem is greatly affected by urban land uses (Oluseyi, 2006). The challenges associated with urban land use change include overcrowding, crime, pollution, increased energy utilization, and a loss of viable farming land (Oluseyi, 2006; Seto \& Kaufmann, 2003). Remote sensing aids the precise procurement of urban land-use information for developing urban districts; however, inadequate remote sensing information limits the acquisition of urban land use data (Herold et al., 2002). Remote sensing can also be used in explaining the spatial distribution between various land uses in urban districts (Rinner \& Hussain, 2011; Yao et al., 2017).

New Braunfels (Figure 1) is a city that falls inside Comal and Guadalupe counties in Texas, USA. The city spans across 44.9 square miles $\left(116 \mathrm{~km}^{2}\right)$ and had a total population of about 90,209 people in 2019 (Lopez, 2018). New Braunfels is considered a suburb just north of San Antonio, and part of the Greater San Antonio metropolitan area (Rogers \& Sletto, 2010). New Braunfels is one of the cities in the US experiencing a massive population influx. It was ranked by the US Census Bureau, the second fastest growing city in the US between July 1, 2016 and July 1, 2017, having an 8\% increase and a total population of 79,152 people (Census Bureau, 2016). This population growth is projected to continue. The city is located in the southeastern part of Comal County, about 48 miles (77 kilometers) southwest of Austin, right between the cities of San Marcos and San Antonio with the Interstate highway 35 (IH-35) cutting through it.

New Braunfels has experienced a 158\% population growth since the year 1990 . New Braunfels has a median age of 37 years and a considerable amount of its land use consists of residential areas (Census Bureau, 2016). Specifically, low density residential land uses make up a large part of the city, alongside commercial, industrial and open space. Commercial land uses occur along IH-35, with

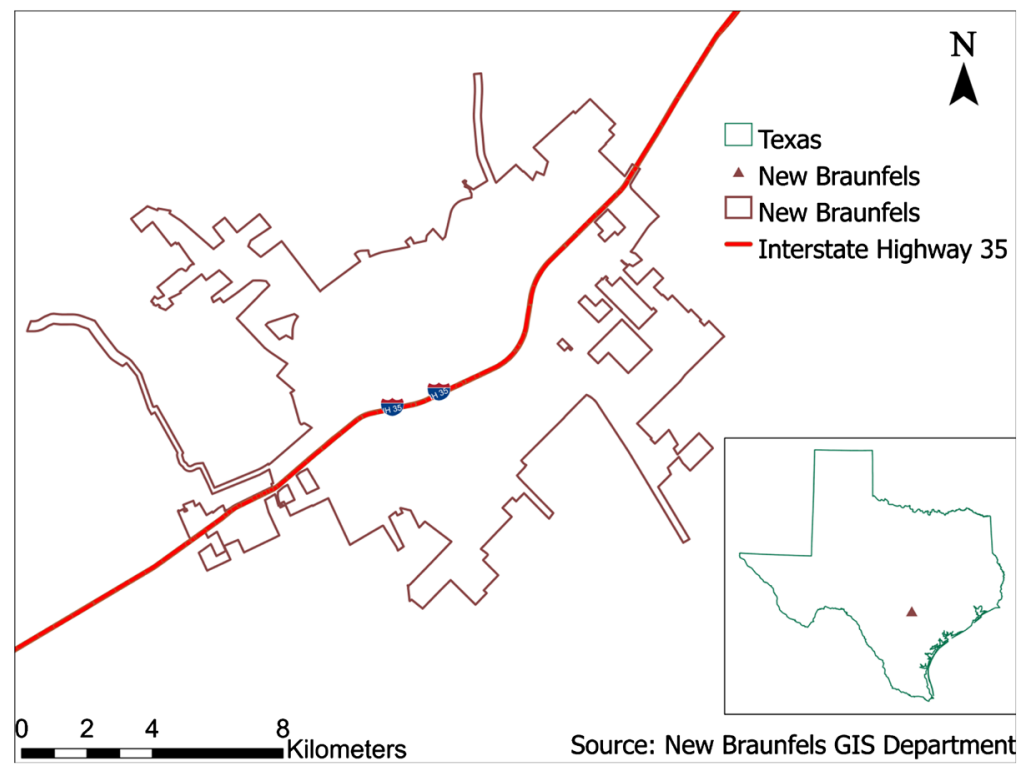

Figure 1. Map showing new Braunfels. 
some pockets of commercial and industrial areas along the parkways of Loop 337, State Highway 46 and FM 306. Waterways together with open space blend together with residential and commercial spaces. Other mixed land use types are seen around Gruene and Creekside areas in New Braunfels. Schools, institutional and government uses are located throughout the city.

\section{Objectives}

This study performs a change detection analysis to uncover those changes in land use that have occurred in the city of New Braunfels, Texas in the last seven years (2013-2020). In this study, we examine those parts of New Braunfels that have had considerable changes in land usage. The specific objectives of this study are as follows:

1) Construct a Normalized Vegetation Index (NDVI) for images from 2013 and 2020 and compare their indices.

2) Classify both images (2013 and 2020) using a supervised classification algorithm into 4 classes namely forest, water, grassland and built-up.

3) Conduct an accuracy assessment to assess classification results.

4) Post-classify the classified images to observe for land cover changes in both years (2013 and 2020)

\section{Data and Methodology}

For this study, the dates of August 31, 2013 and November 5, 2020 were chosen. These dates were specifically selected based on availability of data having significantly less cloud cover $(0.13 \%$ and $0.19 \%$ cloud cover respectively). A relatively high resolution (30 meters) Landsat 8 Imagery for both dates was derived from the United States Geological Survey (USGS) Earth Explorer database (https://earthexplorer.usgs.gov/). The images were already georectified and aligned with the city of New Braunfels boundary shapefile which was sourced from the city of New Braunfels Geographic Information Systems (GIS) department. The New Braunfels city boundary Shapefile was used to clip both Landsat images using ArcGIS Pro version 2.6, a GIS software application. Microsoft EXCEL was used to construct a bar chart to graphically show the observed changes in land use classes in both years.

A land use classification scheme was used to group land and water features in the images into distinctive land use classes. For this, a subset of the pre-defined and widely used 2016 National Land Cover Dataset (NLCD) classification (Jin et al., 2019) was used. This land use classification scheme was modified from the Anderson Land Cover Classification System (Anderson, 1976). The shortlisted classes used in this study are listed in Table 1 below.

\section{Results}

\subsection{Normalized Vegetation Index (NDVI)}

NDVI quantifies the greenness of vegetation and is useful in understanding ve- 
getation density and assessing changes in plant health. NDVI is calculated as a ratio between the red (R) and near infrared (NIR) bands. NDVI was constructed for both images using ERDAS IMAGINE, a remote sensing software application, to assess for any differences in their vegetation indices (Figure 2). From the NDVI map, the areas in white have the highest NDVI while the black areas have low NDVI. The maximum brightness value does indicate the healthiest vegetation cover while the minimum brightness value indicates poor vegetation cover. The black and generally darker areas have the lowest NDVI values. The achievable extreme range from the NDVI equation (Equation (1)) is -1 for poor vegetation and 1 for healthy vegetation cover. From both maps in Figure 2, NDVI for time 2 (November 5,2020 ) was lower for the healthy vegetation range than that of time 1 (August 31, 2013) while time 1 had more concentration of healthy vegetation when compared with time 2. Also time 2 had more poor vegetation cover than in time 1 .

$$
\mathrm{NDVI}=(\mathrm{NIR}-\mathrm{R}) /(\mathrm{NIR}+\mathrm{R})
$$

Table 1. Land use classification.

\begin{tabular}{cc}
\hline Class & Classification Description \\
\hline Water & Open Water-areas of open water \\
\hline Developed & $\begin{array}{l}\text { Developed, High Intensity-consisting highly developed/urban areas where people } \\
\text { reside or work in high numbers. These include apartment complexes, houses, } \\
\text { commercial and industrial buildings. }\end{array}$ \\
\hline Forest & Deciduous, evergreen and mixed forest. \\
\hline Grassland & Grasses, bare land, shrubs and scrubs. \\
\hline
\end{tabular}

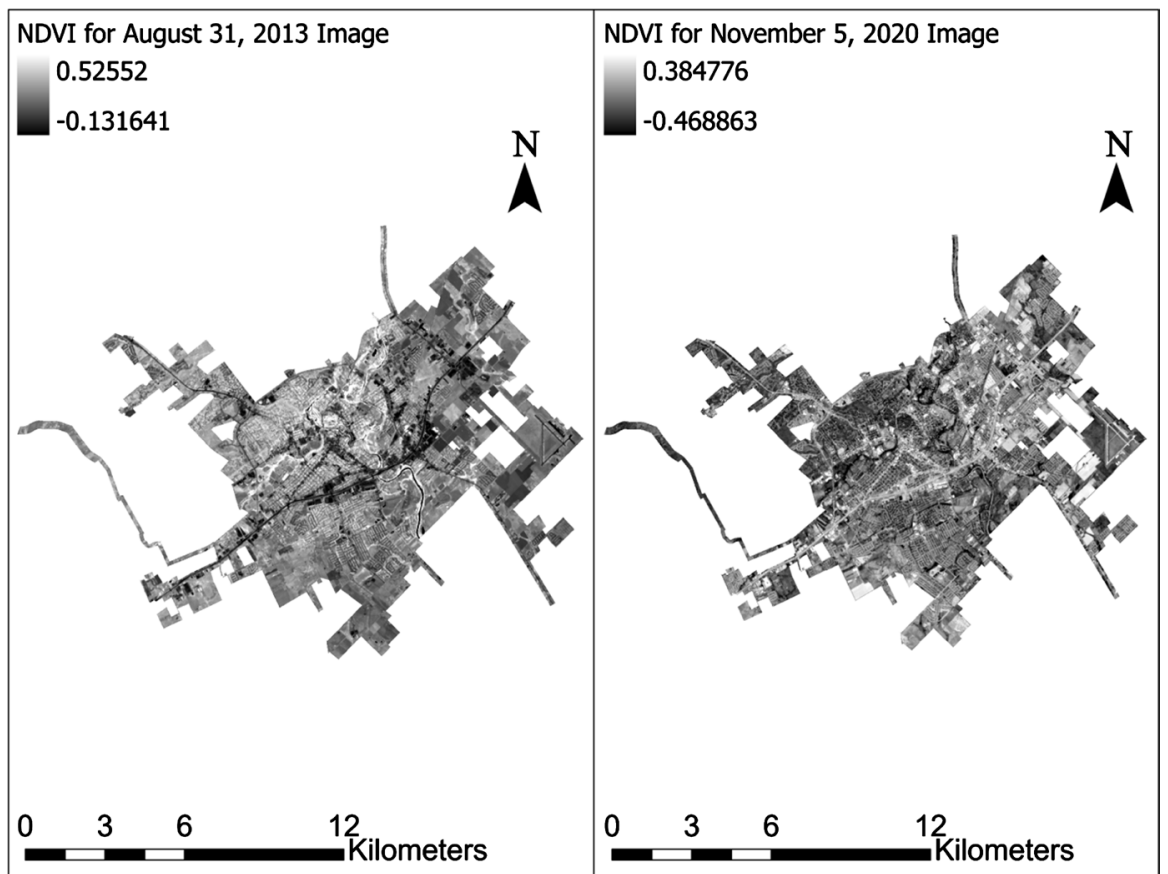

Figure 2. NDVI maps for both timeframes (August 31, 2013 and November 5, 2020). 


\subsection{Land Use/Land Cover Classification of 2013 and 2020 Images}

ERDAS IMAGINE was used to perform a supervised maximum likelihood land cover classification analysis based on the 4 classes defined in Table 1 . As seen on Figure 3, both 2013 and 2020 images were grouped into forest, water, grassland and built-up classes. These classes were used based on prior study and the configuration of the study area. New Braunfels consists predominantly of forests and grasslands with most built-up areas being very close to the major highways.

\subsection{Accuracy Assessment}

An accuracy assessment was performed on the final classified images in Figure 3 to obtain percent accuracy and omission values as well as the Kappa statistic (Table 2 and Table 3). For this, a stratified random method was used to distribute 60 reference points around the 4 land use classes on both classified images. The specific locations of these reference points were then validated using Google Earth Pro to observe for any variations in prior chosen classes. Points that had been previously mis-interpreted were now obvious and as such the accuracy assessment was conducted. An overall accuracy of $68.33 \%$ and $73.33 \%$ was generated respectively for 2013 and 2020 classified images.

\subsection{Post-Classification Change Detection}

Before the change detection process, ERDAS IMAGINE recode tool was used to recode the class values for both previously classified images to ensure that classes in both images had the same codes. Thereafter, a post-classification change detection algorithm using the matrix union tool in ERDAS IMAGINE was applied

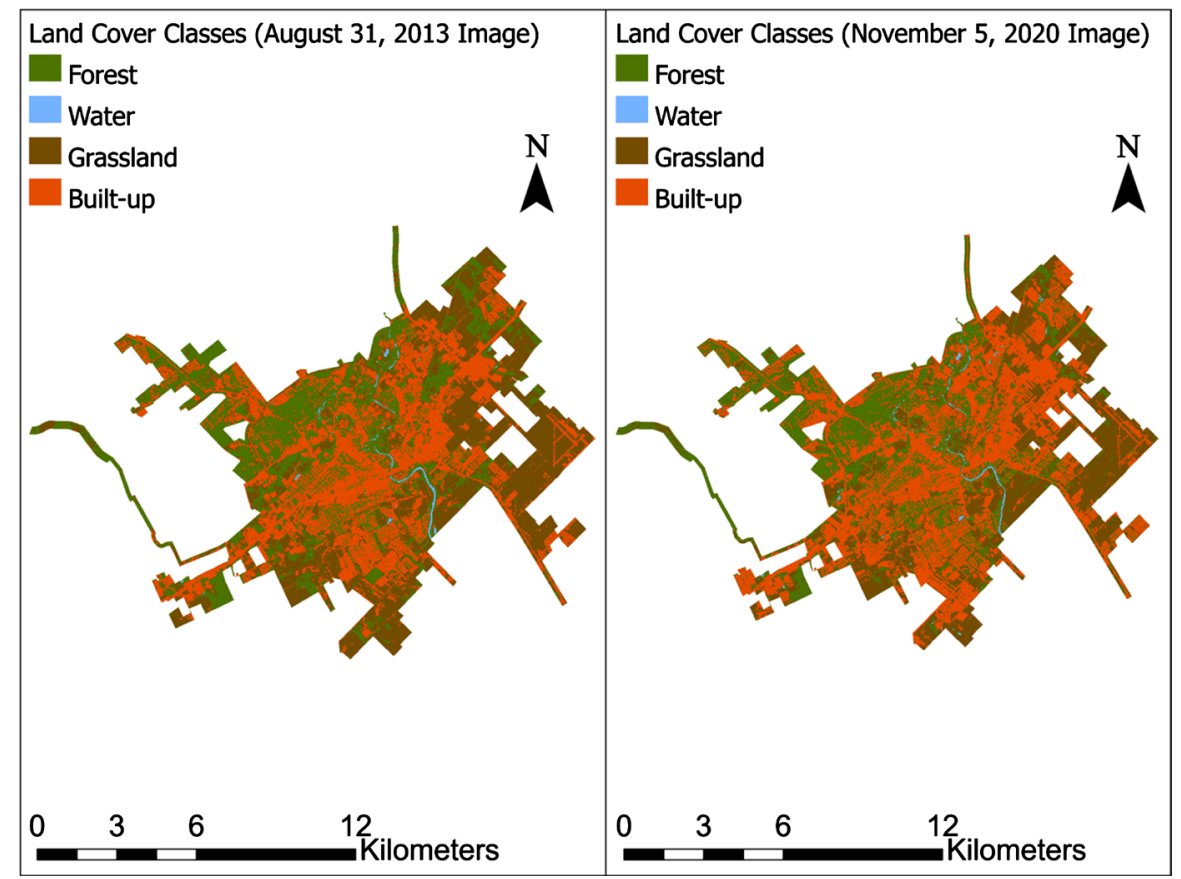

Figure 3. Land cover classes for both sampled images (August 31, 2013 and November 5, 2020). 
Table 2. Accuracy assessment for August 31 $1^{\text {st }}, 2013$ image.

CLASSIFICATION ACCURACY ASSESSMENT REPORT (August 31, 2013 Image)

\begin{tabular}{cccccc}
\hline ACCURACY TOTALS & \multicolumn{1}{c}{ Reference } \\
Totals & $\begin{array}{c}\text { Classified } \\
\text { Totals }\end{array}$ & $\begin{array}{c}\text { Number } \\
\text { Correct }\end{array}$ & $\begin{array}{c}\text { Producers } \\
\text { Accuracy }\end{array}$ & $\begin{array}{c}\text { Users } \\
\text { Accuracy }\end{array}$ \\
\hline Forest & 17 & 16 & 12 & $70.59 \%$ & $75.00 \%$ \\
Water & 4 & 10 & 4 & $100.00 \%$ & $40.00 \%$ \\
Grassland & 23 & 17 & 13 & $56.52 \%$ & $76.47 \%$ \\
Built-up & 16 & 17 & 12 & $75.00 \%$ & $70.59 \%$ \\
Totals & 60 & 60 & 41 & &
\end{tabular}

Overall Classification Accuracy $=68.33 \%$

KAPPA (K^) STATISTICS

Overall Kappa Statistics $=0.5657$

Conditional Kappa for each Category.

$\begin{array}{cc}\text { Class Name } & \text { Kappa } \\ \text { Forest } & 0.6512 \\ \text { Water } & 0.3571 \\ \text { Grassland } & 0.6184 \\ \text { Built-up } & 0.5989\end{array}$

Table 3. Accuracy assessment for November $5^{\text {th }}, 2020$ image.

\begin{tabular}{cccccc}
\hline CLASSIFICATION ACCURACY ASSESSMENT REPORT (November & 5, 2020 Image) & \\
\hline ACCURACY TOTALS & & & & & \\
\hline Class Name & $\begin{array}{c}\text { Reference } \\
\text { Totals }\end{array}$ & $\begin{array}{c}\text { Classified } \\
\text { Totals }\end{array}$ & $\begin{array}{c}\text { Number } \\
\text { Correct }\end{array}$ & $\begin{array}{c}\text { Producers } \\
\text { Accuracy }\end{array}$ & $\begin{array}{c}\text { Users } \\
\text { Accuracy }\end{array}$ \\
\hline Grassland & 19 & 14 & 12 & $63.16 \%$ & $85.71 \%$ \\
Built-up & 20 & 22 & 16 & $80.00 \%$ & $72.73 \%$ \\
Water & 7 & 10 & 7 & $100.00 \%$ & $70.00 \%$ \\
Forest & 14 & 14 & 9 & $64.29 \%$ & $64.29 \%$ \\
Totals & 60 & 60 & 44 & &
\end{tabular}

Overall Classification Accuracy $=73.33 \%$

KAPPA $\left(K^{\wedge}\right)$ STATISTICS

Overall Kappa Statistics $=0.6347$

Conditional Kappa for each Category.

$\begin{array}{cc}\text { Class Name } & \text { Kappa } \\ \text { Grassland } & 0.7909 \\ \text { Built-up } & 0.5909 \\ \text { Water } & 0.6604 \\ \text { Forest } & 0.5342\end{array}$


on both classified images to examine for any changes in land cover classes between time 1 (August 31, 2013) and time 2 (November 5, 2020). ArcGIS Pro version 2.6 was used to create a map of the post-classification change detection image (Figure 4). Furthermore, the summary report of matrix tool was used to generate the numeric count of changes per class between time 1 and time 2 (Tables 4-7). Classes that had a considerable amount of change are shown on the map in Figure 4. The water class did not have any significant change; hence, it is not shown on the map. Grassland, built-up and forest classes had the most

Table 4. Change summary of forest class between time 1 and time 2 .

\begin{tabular}{cccc}
\hline Class name: Forest (Time 1) & & & \\
\hline Class Name (Time 2) & Count (Pixels) & $\%$ & Hectares \\
\hline Forest & 104,802 & 67.7 & 2358.045 \\
Water & 1120 & 0.72 & 25.2 \\
Grassland & 24,313 & 15.71 & 547.043 \\
Built-up & 24,565 & 15.87 & 552.712 \\
Total & 154,800 & 100 & 3483 \\
Zonal Statistics: & & & \\
Majority & 1 & Mean & 1.7974 \\
Median & 1 & Minimum & 1 \\
Maximum & 4 & Range & 4 \\
Diversity & 4 & Std. Deviation & 1.1949 \\
Majority Count & 104,802 & Majority (\%) & 67.7016 \\
Sum & 278,241 & & \\
\hline
\end{tabular}

Table 5. Change summary of water class between time 1 and time 2 .

\begin{tabular}{cccc}
\hline Class name: Water (Time 1) & & & \\
\hline Class Name (Time 2) & Count (Pixels) & $\%$ & Hectares \\
\hline Forest & 721 & 26.06 & 16.223 \\
Water & 1800 & 65.05 & 40.5 \\
Grassland & 191 & 6.9 & 4.297 \\
Built-up & 55 & 1.99 & 1.238 \\
Total & 2767 & 100 & 62.258 \\
Zonal Statistics: & & & \\
Majority & 2 & Mean & 1.8482 \\
Median & 2 & Minimum & 1 \\
Maximum & 4 & Range & 4 \\
Diversity & 4 & Std. Deviation & 0.6215 \\
Majority Count & 1800 & Majority (\%) & 65.0524 \\
Sum & 5114 & & \\
\hline
\end{tabular}


Table 6. Change summary of Grassland class between time 1 and time 2 .

\begin{tabular}{cccc}
\hline Class name: Grassland (Time 1) & & & \\
\hline Class Name (Time 2) & Count (Pixels) & $\%$ & Hectares \\
\hline Forest & 15,041 & 8.46 & 338.423 \\
Water & 102 & 0.06 & 2.295 \\
Grassland & 112,104 & 63.04 & 2522.34 \\
Built-up & 50,588 & 28.45 & 1138.23 \\
Total & 177,835 & 100 & 4001.287 \\
Zonal Statistics: & & & \\
Majority & 3 & Mean & 3.1147 \\
Median & 3 & Minimum & 1 \\
Maximum & 4 & Range & 4 \\
Diversity & 4 & Std. Deviation & 0.7811 \\
Majority Count & 112,104 & Majority (\%) & 63.0382 \\
Sum & 553,909 & & \\
\hline
\end{tabular}

Table 7. Change summary of Built-up class between time 1 and time 2 .

\begin{tabular}{cccc}
\hline Class name: Built-up (Time 1) & & & \\
\hline Class Name (Time 2) & Count (Pixels) & $\%$ & Hectares \\
\hline Forest & 26,849 & 14.27 & 604.102 \\
Water & 60 & 0.03 & 1.350 \\
Grassland & 11,813 & 6.28 & 265.793 \\
Built-up & 149,377 & 79.41 & 3360.983 \\
Total & 188,099 & 100 & 4232.228 \\
Zonal Statistics: & & & \\
Majority & 4 & Mean & 3.5083 \\
Median & 4 & Minimum & 1 \\
Maximum & 4 & Range & 4 \\
Diversity & 4 & Std. Deviation & 1.0521 \\
Majority Count & 149,377 & Majority (\%) & 79.414 \\
Sum & 659,916 & & \\
\hline
\end{tabular}

changes between 2013 and 2020 .

The histogram values for the corresponding land cover classes of the previously classified images in Figure 3 were populated in a chart (Figure 5) using Microsoft EXCEL to graphically observe for generic changes in time 1 and time 2. From the chart, a considerable amount of change (an increase of 36,486 pixels) is observed from time 2 for the Built-up class. This is also relatable to the decreased number of pixels for grassland and forest land cover classes in time 2. These vegetated areas could have been cleared out for construction purposes, 


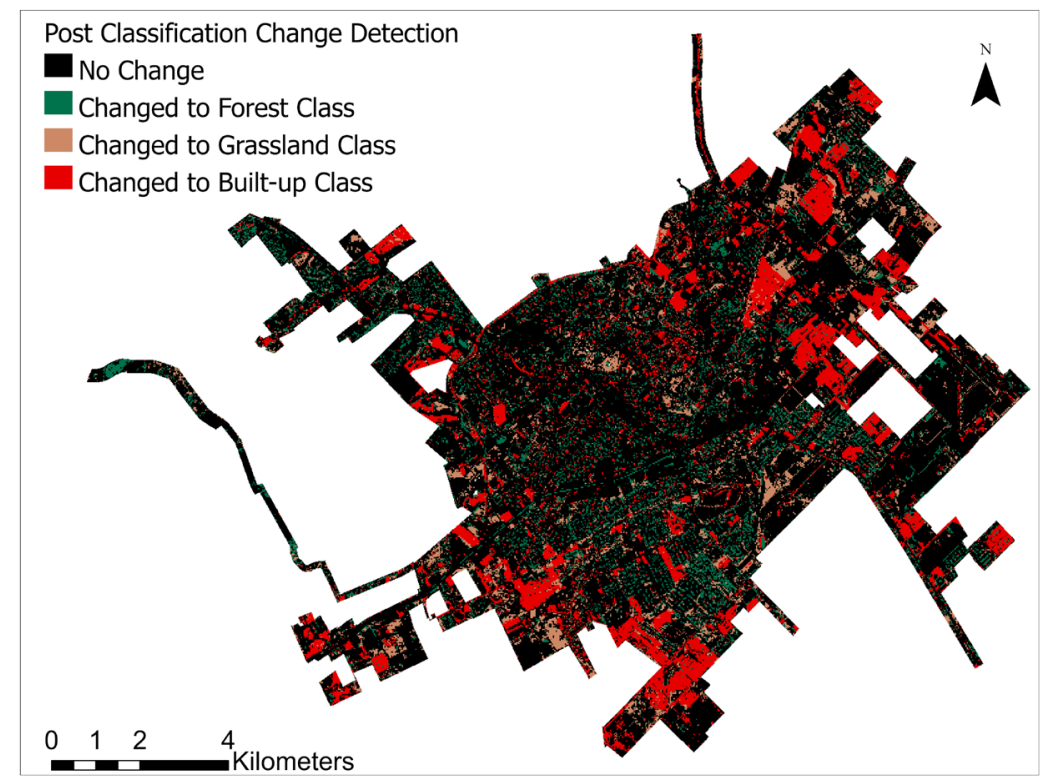

Figure 4. Considerable changes in land cover between August 31, 2013 (time 1) and November 5, 2020 (time 2).

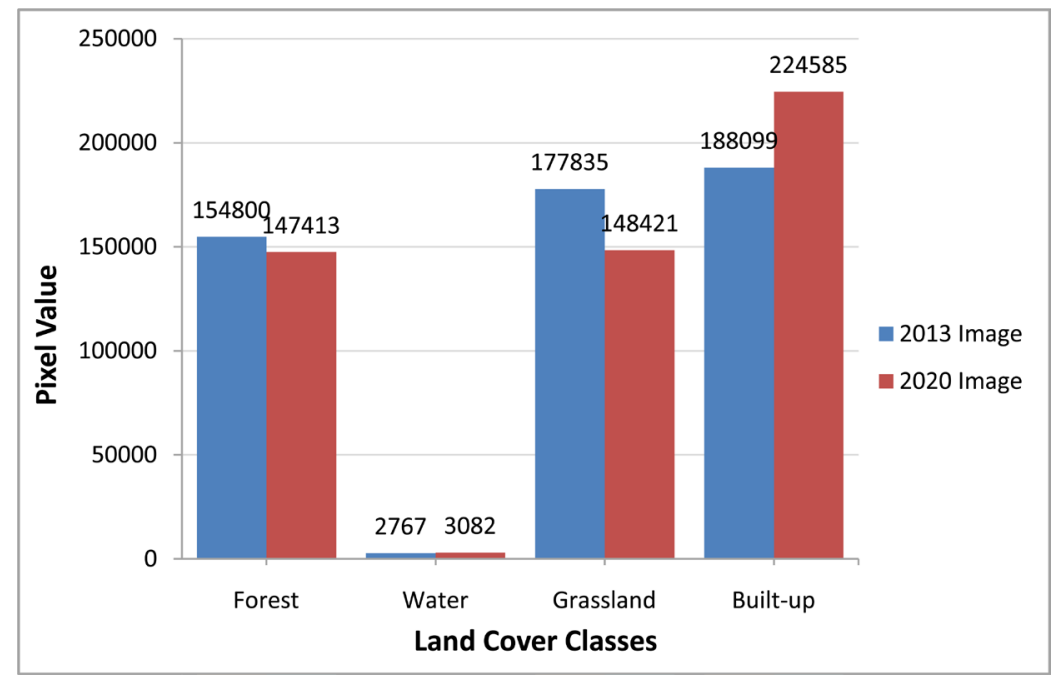

Figure 5. Pixel value change between time 1 (2013 image) and time 2 (2020 image).

hence the decreased number of pixels. Water land cover class in time 2 had a little change from time 1 and this could be attributed to the presence of swimming pools and other man made water bodies which were present in time 2 image.

\section{Discussion}

This study examined the city of New Braunfels, Texas, USA to assess for any observable land cover/land use changes from August 31, 2013 to November 5, 2020. From the results, we noticed a considerable change in pixels in the built-up class (with an increase of 36,486 pixels from time 1 to time 2) followed by the grassland class which was a decrease of 29,414 pixels from time 1 to time 2. Forest class also had a decrease of 7387 pixels from time 1 to time 2 and Water class 
had the least gain of only 315 pixels more than time 1 .

From the generic land cover change chart on Figure 5, we see again how the built-up class changed massively in the last seven years. This considerable change comes mainly as a result of the developments of residential and other urban land uses in New Braunfels. This also comes as a result of the continuous influx of people into the city which has created the need to clear out forests and possibly, cultivated lands in order to construct new apartment complexes and other urban structures. The NDVI change from time 1 to time 2 can also be attributed to the extent of change in the built-up class especially surrounding the main highways in the city (IH-35 and highway 46). Most of these parts of the city were covered with dense and healthy vegetation in time 1 but had been cleared out in time 2 .

In the accuracy assessment process, we used 60 and 80 points ( 2 scenarios) distributed around the 4 land cover classes using both stratified random and random sampling methods. However, we observed, after 3 trials, that the water land cover class had got only a few points compared to the 3 other classes (grassland, built-up and forest) on both images. This may have produced a fairly biased result and impacted on both the users and producer's accuracy values. This limitation was in part due to the water class having a limited number of pixels (only a very small part in both images had water). Perhaps, it would be helpful if one could manually place the reference points on the images instead of depending on the randomly generated points but again, this could aggravate user bias. Another solution to this could be to increase the number of randomly generated points. Another limitation to this study was that of the spatial resolution of the images used in this study. Perhaps, higher spatial resolution images could have impacted on the producers, users and overall accuracy assessment (Reba \& Seto, 2020; Zhou et al., 2018).

\section{Conclusion}

Results from this study can aid the appropriate bodies in planning properly for the city of New Braunfels and other cities as regards resource allocation and distribution. As noted by (Dong et al., 2020) in their land use land cover change study of Changchun, most cities place their emphasis on economic development which often lead to increased pressure on urban land, as such, urban planners should explore strategies to promote urban sustainable development. Cities can also apply land use change methods in determining areas where growth and development need to be promoted as well as where they need to be controlled.

\section{Author Contributions}

All authors of this work performed substantial contributions to conception, design, analysis and writing and design of this article. All authors have read the manuscript for important intellectual content and approved the final version for publication. 


\section{Conflicts of Interest}

The authors declare no conflicts of interest regarding the publication of this paper.

\section{References}

Anderson, J. R. (1976). A Land Use and Land Cover Classification System for Use with Remote Sensor Data. No. 964, Washington DC, WA: US Government Printing Office. https://doi.org/10.3133/pp964

Census Bureau. (2016). Five of the Nation's Eleven Fastest-Growing Cities are in Texas. In United States Census Bureau. http://www.census.gov/newsroom/press-releases/2016/cb16-81.html

Dong, Y. L., Ren, Z. B., Fu, Y., Miao, Z. H., Yang, R., Sun, Y. H., \& He, X. Y. (2020). Recording Urban Land Dynamic and Its Effects during 2000-2019 at 15-m Resolution by Cloud Computing with Landsat Series. Remote Sensing, 12, 2451.

https://doi.org/10.3390/rs12152451

Herold, M., Scepan, J., \& Clarke, K. C. (2002). The Use of Remote Sensing and Landscape Metrics to Describe Structures and Changes in Urban Land Uses. Environment and Planning A, 34, 1443-1458. https://doi.org/10.1068/a3496

Hersperger, A. M., Oliveira, E., Pagliarin, S., Palka, G., Verburg, P., Bolliger, J., \& Grădinaru, S. (2018). Urban Land-Use Change: The Role of Strategic Spatial Planning. Global Environmental Change, 51, 32-42. https://doi.org/10.1016/j.gloenvcha.2018.05.001

Jin, S., Homer, C., Yang, L., Danielson, P., Dewitz, J., et al. (2019). Overall Methodology Design for the United States National Land Cover Database 2016 Products. Remote Sensing, 11, 2971. https://doi.org/10.3390/rs11242971

Lasode, M. K., Chow, T. E., Hagelman, R. R., Blanchard, R. D., Lasode, O. O., \& Iyanda, A. E. (2021). The Impact of Homelessness in Social Vulnerability Assessment: A Case Study of Austin, Texas. Social and Economic Geography, 6, 1-12. https://doi.org/10.12691/seg-6-1-1

Lopez, A. A. (2018). Impacts of Flooding on the Hispanic Community in New Braunfels. Texas: A Mixed Method Approach to Understanding Flood Vulnerability. San Marcos, TX: Texas State University.

Oluseyi, O. F. (2006). Urban Land Use Change Analysis of a Traditional City from Remote Sensing Data: The Case of Ibadan Metropolitan Area, Nigeria. Humanity \& Social Sciences Journal, 1, 42-64.

Reba, M., \& Seto, K. C. (2020). A Systematic Review and Assessment of Algorithms to Detect, Characterize, and Monitor Urban Land Change. Remote Sensing of Environment, 242, Article ID: 111739. https://doi.org/10.1016/j.rse.2020.111739

Rogers, J. D. J., \& Sletto, B. (2010). A Study of Library Usage in the City of New Braunfels: Using Spatial Analysis to Inform Service Locations.

Rinner, C., \& Hussain, M. (2011). Toronto's Urban Heat Island-Exploring the Relationship between Land Use and Surface Temperature. Remote Sensing, 3, 1251-1265. https://doi.org/10.3390/rs3061251

Seto, K. C., \& Kaufmann, R. K. (2003). Modeling the Drivers of Urban Land Use Change in the Pearl River Delta, China: Integrating Remote Sensing with Socioeconomic Data. Land Economics, 79, 106-121. https://doi.org/10.2307/3147108

Verburg, P. H., Crossman, N., Ellis, E. C., Heinimann, A., Hostert, P., Mertz, O., Grau, R. et al. (2015). Land System Science and Sustainable Development of the Earth System: A 
Global Land Project Perspective. Anthropocene, 12, 29-41.

https://doi.org/10.1016/j.ancene.2015.09.004

Yao, Y., Li, X., Liu, X., Liu, P., Liang, Z., Zhang, J., \& Mai, K. (2017). Sensing Spatial Distribution of Urban Land Use by Integrating Points-of-Interest and Google Word2Vec Model. International Journal of Geographical Information Science, 31, 825-848.

https://doi.org/10.1080/13658816.2016.1244608

Zhou, W., Wang, J., Qian, Y., Pickett, S. T., Li, W., \& Han, L. (2018). The Rapid but "Invisible" Changes in Urban Greenspace: A Comparative Study of Nine Chinese Cities. Science of the Total Environment, 627, 1572-1584.

https://doi.org/10.1016/j.scitotenv.2018.01.335 